\title{
Reduced recombination and enhanced UV-assisted photocatalysis by highly anisotropic titanates from electrospun $\mathrm{TiO}_{2}-\mathrm{SiO}_{2}$ nanostructures $\uparrow$
}

\begin{abstract}
Veluru Jagadeesh Babu, ${ }^{\star a}$ Sesha Vempati ${ }^{a}$ and Seeram Ramakrishna*bc
The surface areas of electrospun fibers/rice grain-shaped nanostructures of $\mathrm{TiO}_{2}-\mathrm{SiO}_{2}$ composites were further enhanced after transforming them into thorn or sponge shaped titanates via selective leaching of $\mathrm{SiO}_{2}$, which was reported by our group previously [RSC Adv., 2012, 2, 992]. In this study, we report on their application in photocatalytic activity (PCA) when juxtaposed with photoluminescence (PL). Two defect related bands are observed in $\mathrm{PL}$ and their origin is discussed in relation to calcination, crystallization and nucleation effects. The relative PL intensity for sponge shapes was the lowest and hence had the lowest radiative recombination, which suggests carrier trapping at defect centers. This enables the charge carriers to migrate to the surface and participate in the PCA. The results of PCA suggested that the sponge-shaped titanate exhibits the highest degradation rate among all samples. A plausible mechanism for the differences in PCA is proposed based on the variation in the defect-densities.
\end{abstract}

Received 17th April 2014 Accepted 13th June 2014

DOI: $10.1039 / c 4 r a 03498 h$

www.rsc.org/advances selectively removed via alkali mediated chemical conversion ${ }^{31,32}$ and subsequent heat treatment. Besides, they combine the properties of conventional titanate (ion-exchange) ${ }^{33}$ and titania (photocatalyst). ${ }^{7,34}$ On the other hand, the wide band gap energy of these titanates ( $3.8 \mathrm{eV}$ for nanosheets composed of sponges; and $3.2 \mathrm{eV}$ of anatase $\left.\mathrm{TiO}_{2}\right),{ }^{35,36}$ exhibit optical absorption in UV region and make them suitable in photocatalysis ${ }^{8}$ and photoelectric applications. Various studies on photocatalytic activity (PCA) and its enhancement is seen in literature for example, decomposition of acetic acid, ${ }^{37}$ organic/inorganic pollutants, heavy metal ions and dyes from water ${ }^{11,33,38}$ etc. Similar to other semiconductors, in the case of titanates, high surface area influences the optoelectronic properties where an explicit effect is reflected in photoluminescence (PL) attracting a lot of research attention. Recently, ${ }^{29,30}$ the optical emission properties of $\mathrm{ZnO}$ and $\mathrm{ZnO}-\mathrm{TiO}_{2}$ nano/hetero-structures are juxtaposed with PCA which consider intrinsic defects. In contrast, the present study deals with the defects which are associated with extrinsic as well as intrinsic defects in titanates.

The synthesis of thorn and sponge shaped titanates from $\mathrm{TiO}_{2}-\mathrm{SiO}_{2}$ electrospun nanofibers/rice grain shaped structures were already been reported from our group previously. ${ }^{39,40}$ In continuation, here we report an important application in which we have employed the nanostructures as catalysts and tests their abilities. The emission intensity of $\mathrm{e} / \mathrm{h}$ recombination is monitored across the samples (sponge and thorn shapes) and a correlation is obtained for the differences in PCA. $\mathrm{TiO}_{2}-\mathrm{SiO}_{2}$ nanofibers/rice grains shapes, upon alkali $(\mathrm{NaOH})$ treatment yielded the structures with high surface area which facilitates the excellent photocatalytic properties for the degradation of an organic dye (Alizarin Red S). We anticipate that our 
investigations may help further understanding of various titanate nanomaterials and accelerate in the application potential.

\section{Experimental}

\section{Materials}

Titanium(Iv) isopropoxide (TiP, 97\%), poly(vinylacetate) (PVAc, $\left.M_{\mathrm{w}}=0.5 \times 10^{6}\right)$, poly(vinylpyrrolidone: PVP, $M_{\mathrm{w}}=1.30 \times 10^{6}$, Aldrich, Steinhseim, Germany), $N, N$-dimethyl acetamide (DMAc, anhydrous 99.8\%), and tetraethoxysilane (TES, 99\%) were obtained from Sigma-Aldrich (Steinheim, Germany). Acetic acid (99.7\%) was obtained from LAB-SCAN Analytical Sciences, Thailand. Ethanol (absolute, Fischer scientific, Leicestershire, UK), Alizarin Red S dye (ARS) was obtained from Sigma-Aldrich, China. All the chemicals used without any further purification.

\section{Preparation}

$\mathrm{TiO}_{2}-\mathrm{SiO}_{2}-\mathbf{P V P}$ fibers. Methodology for the fabrication of the nanofibers is similar to our earlier reports. ${ }^{39,40}$ In brief, approximately $0.6 \mathrm{~g}$ of PVP, $14 \mathrm{~mL}$ of ethanol were thoroughly mixed for $\sim 6 \mathrm{~h}$. About $4 \mathrm{~mL}$ of glacial acetic acid was added to the above solution under stirring. This step was followed by the addition of three different sets of TiP $(1.75,1.5$ or $1 \mathrm{~mL})$ and TES $(0.25,0.5$ or $1 \mathrm{~mL})$ solutions separately i.e. the three different solutions were (1) $1.75 \mathrm{~mL}$ of TiP $+0.25 \mathrm{~mL}$ of TES, (2) $1.5 \mathrm{~mL}$ of $\mathrm{TiP}+0.5 \mathrm{~mL}$ of TES, and (3) $1 \mathrm{~mL}$ of TiP $+1 \mathrm{~mL}$ of TES. The total mixture was stirred continuously for $\sim 12 \mathrm{~h}$ to obtain homogeneity. The well mixed solution, (1), was taken into a $10 \mathrm{~mL}$ syringe with $27 \mathrm{G} \times 1 / 2$ needle. The optimized conditions for continuous electrospinning for the $\mathrm{TiO}_{2}$ was described in our previous reports. ${ }^{4-44}$ In the present context, the flow rate maintained as $0.8 \mathrm{~mL} \mathrm{~h}^{-1}$, the distance between the tip of the needle and collector was about $10 \mathrm{~cm}$, and a high voltage of $30 \mathrm{kV}$ is applied. The humidity levels approximately $\sim 50 \%$ were maintained inside the electrospinning chamber. From our previous findings, ${ }^{40}$ the solution (2) \& (3) were unsuccessful to yield continuous nanofibers because of the high level of $\mathrm{SiO}_{2}$ precursor concentrations.

$\mathbf{T i O}_{2}-\mathbf{S i O}_{2}-\mathbf{P V A c}$ fibers. The preparation is similar to the earlier case, expect, PVP is replaced with PVAc. In a typical procedure, $2.4 \mathrm{~g}$ of PVAc was dissolved in $20 \mathrm{~mL}$ of DMAc. This was followed by the addition of $4 \mathrm{~mL}$ acetic acid and a mixture of $1.75 \mathrm{~mL}$ TiP $+0.25 \mathrm{~mL}$ TES. The mixture was stirred for $\sim 12 \mathrm{~h}$ for homogeneity and subjected to electrospinning. We have also attempted higher $\mathrm{SiO}_{2}$ concentrations as mentioned earlier, however, unsuccessful for $(0.5$ and $1 \mathrm{~mL}$ of TES in 1.5 or $1 \mathrm{~mL}$ of TiP, respectively).

As-spun $\left(\mathrm{TiO}_{2}-\mathrm{SiO}_{2}-\mathrm{PVP}\right.$ or $\left.\mathrm{TiO}_{2}-\mathrm{SiO}_{2}-\mathrm{PVAc}\right)$ fibers were removed from the collector and the freestanding mat is subjected to calcination $\left(500{ }^{\circ} \mathrm{C}\right.$ for $\left.1 \mathrm{~h}\right)$ to remove the polymer. Furthermore, $\mathrm{TiO}_{2}-\mathrm{SiO}_{2}-\mathrm{PVAc}$ composite nanofibers were calcined at $700{ }^{\circ} \mathrm{C}$. About $500 \mathrm{mg}$ of the composite nanostructures was treated with $100 \mathrm{~mL}$ of $5 \mathrm{M} \mathrm{NaOH}$ solution (in glass vials) at $80{ }^{\circ} \mathrm{C}$ in an oven for $24 \mathrm{~h}$. This alkali treatment will etch the $\mathrm{SiO}_{2}$ while facilitating the structural rearrangement of
$\mathrm{TiO}_{2}$. The treated material was washed several times with deionized water and finally with ethanol. This was then dried in an oven at $80{ }^{\circ} \mathrm{C}$. The materials thus obtained were subjected to further characterization. Experiments have also been conducted with $10 \mathrm{M} \mathrm{NaOH}$ solution under similar condition; as a result, the nanostructures were disintegrated into nanoparticles. After $\mathrm{NaOH}$ treatment $\mathrm{TiO}_{2}-\mathrm{SiO}_{2}-\mathrm{PVP} / 500{ }^{\circ} \mathrm{C}$ (thorn), $\mathrm{TiO}_{2}-\mathrm{SiO}_{2}-$ $\mathrm{PVAc} / 500{ }^{\circ} \mathrm{C}$ (sponge) and $\mathrm{TiO}_{2}-\mathrm{SiO}_{2}-\mathrm{PVAc} / 700{ }^{\circ} \mathrm{C}$ samples are referred as $S_{1}, S_{2}$ and $S_{3}$, respectively.

\section{Characterization}

Before and after the calcination the samples were analyzed under scanning electron microscopy (SEM: JEOL JSM-6701F). Prior to the observation, nominal $5 \mathrm{~nm}$ gold was coated. Highresolution transmission electron microscopy (HRTEM) and selected area electron diffraction (SAED) were performed using a JEOL 3010 TEM. The samples were dispersed in methanol, then a droplet of the solution is collected on carbon-coated copper grid and dried in vacuum. X-ray diffraction (XRD) patterns were recorded from Bruker-AXS D8 ADVANCE. PL was carried out using (Fluorolog, Horiba Jobin Yvon) at an excitation wavelength $\left(\lambda_{\text {ex }}\right)$ of $\sim 400 \mathrm{~nm}$. The complete procedure is given in our previous publications. ${ }^{\mathbf{6} 41}$ The dye is exposed to an UV irradiation $(\sim 390 \mathrm{~nm})$ in the presence of catalyst $(\sim 5 \mathrm{mg})$ and the degradation rate is quantified via monitoring the optical absorption (UV-3600, Shimadzu) of the dye at different exposure times (SI-1 $\dagger$ ). X-ray photoelectron spectroscopy (XPS) and BET surface area measurements were already published by our group. ${ }^{39}$

\section{Results and discussion}

Fig. 1(a) shows the SEM images of $\mathrm{TiO}_{2}-\mathrm{SiO}_{2}$ nanofibers produced from the calcination of $\mathrm{TiO}_{2}-\mathrm{SiO}_{2}-\mathrm{PVP}$ precursor fibers. The fibers are found to be rather uniform throughout their lengths without any typical defects such as beads. The average diameter of the fiber is found to be $340 \mathrm{~nm}$. Gaussian distribution is assumed and the fit is shown in Fig. 1(b). Fig. 1(c) shows the SEM images of the nanostructures obtained after the $\mathrm{NaOH}$ treatment followed by $\mathrm{H}_{2} \mathrm{O}$ and ethanol washing. During the $\mathrm{NaOH}$ treatment, $\mathrm{SiO}_{2}$ leaches from fibers forming thorn like structure. These thorn-like nanostructures can be seen more clearly at high magnification (Fig. 1(d)). The morphological evolution of thorn shaped nanostructures will be discussed latter in this section.

SEM image of rice grain-shaped structures and subsequent sponge shaped structures are shown in Fig. 2. From Fig. 2(a) the average diameter of rice grain is found to be $\sim 350 \mathrm{~nm}$. The rice grain morphology was completely lost upon treatment of $\mathrm{NaOH}$ forming highly anisotropic nanostructures. The SEM image depicted in Fig. 2(b) and (c) shows sponge-shaped morphology $\left(\mathrm{S}_{2}\right)$. Based on the earlier investigation ${ }^{39}$ it is the case that the selective leaching of $\mathrm{SiO}_{2}$ as well as reorganization of $\mathrm{Ti}$ atoms play a crucial role in the formation of the sponge like structures. It is also notable that this structure is rather uniform throughout the sample indicating the 

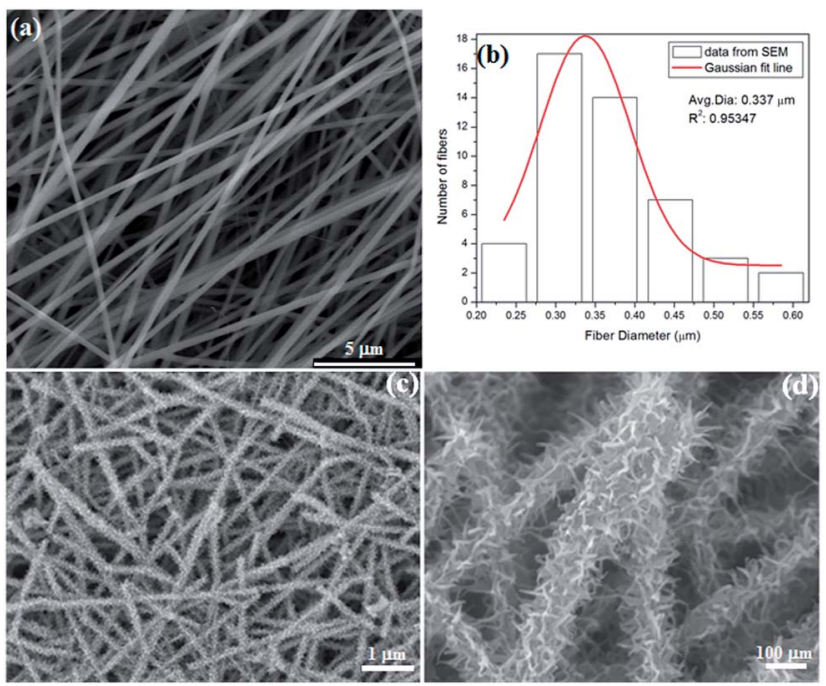

Fig. 1 SEM images of (a) $\mathrm{TiO}_{2}-\mathrm{SiO}_{2}-\mathrm{PVP}$ nanofiber (b) distribution of diameters with a Gaussian fit superimposed (c) titanates with thorn shaped structures on surfaces obtained by the leaching of $\mathrm{SiO}_{2}$ from $\mathrm{TiO}_{2}-\mathrm{SiO}_{2}$ composite nanofibers $(5 \mathrm{M} \mathrm{NaOH})$ and (d) high resolution images of thorn structures.
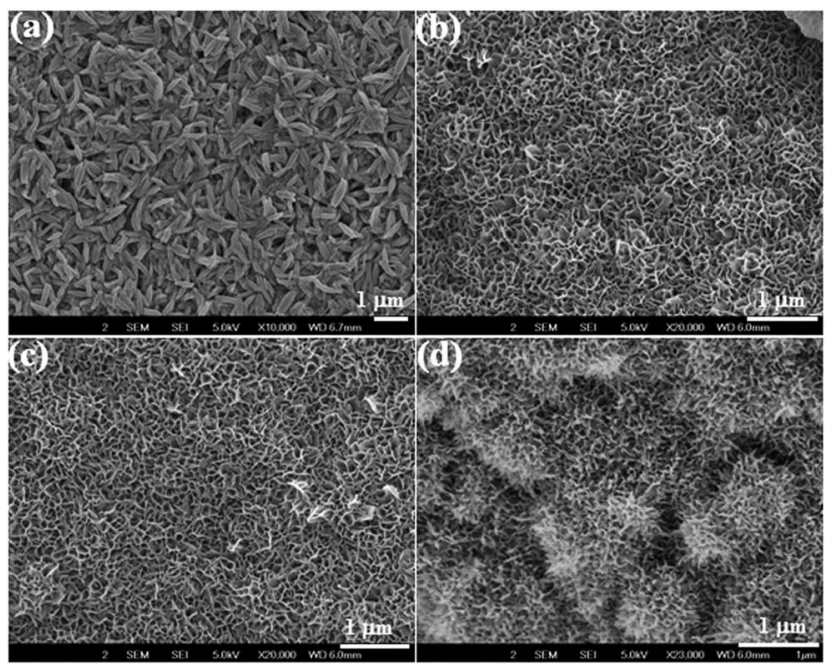

Fig. 2 SEM images of (a) rice grain shapes (b) sponge like structures (c) sponge shapes at another location of the sample and (d) disintegrated shapes at few isolated spots after $700{ }^{\circ} \mathrm{C}$ calcination.

potentiality of this process. Furthermore, in the case of $S_{3}$ the sponge structure is more or less disintegrated (Fig. 2(d)) where the porous structure was spotted in a few isolated regions of the sample and a closer examination resembles a spongeshaped morphology.

In the following we discuss the mechanism behind these structures. It is clear that the morphological differences are because of the polymer that is complexed with titanium and or silicon precursor. Here such interactions are considered while the bonding between $\mathrm{PVP}-\mathrm{TiO}_{2}$ and $\mathrm{PVAc}-\mathrm{TiO}_{2}$ are referred as $\Delta_{1}$ and $\Delta_{2}$, respectively; see the schematic diagram in Fig. 3. In both cases the dangling unsaturated oxygen is active for

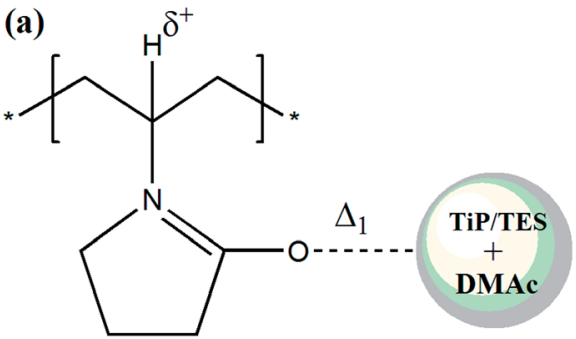

(b)

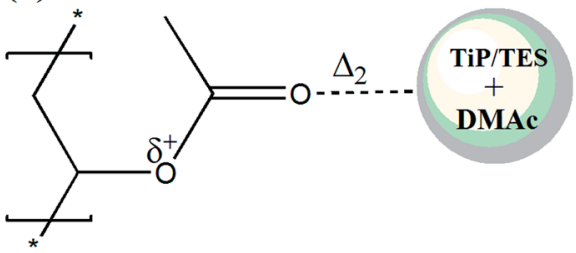

Fig. 3 Interaction between titanium dioxide with (a) PVP and (b) PVAc.

interaction, where we need to note the variance in the chemical environment. PVP is a well studied surfactant ${ }^{45}$ where its interaction not just limited to the oxygen, but also to the alkyl chain. In the case of PVP the oxygen attached to a heterocyclic compound (Fig. 3(a)), while in the case of PVAc it is to an alkyl chain (Fig. 3(a)). If we consider the strengths of $\Delta_{1}$ and $\Delta_{2}$ it is could be case that the former is stronger than the latter. During the calcination, $\Delta_{1}$ results in lower mobility of the molecules, in contrast $\Delta_{2}$ leaves comparatively higher mobility. Furthermore, it should be noted that the relatively higher $\Delta_{1}$ of PVP allows it to be distributed uniformly. Hence in the case of $S_{1}$ sample, the fiber structure is retained even after calcination followed by leaching of $\mathrm{SiO}_{2}$. The case with PVAc of course is not similar to that of PVP, where we can expect microscale phase separation (solubility mismatch) for the former case causing non-uniform distribution of the polymer. This phase separation under limited interaction takes elongated shapes. ${ }^{46}$ Consequently, when the sample is subjected to calcination, PVAc is decomposed leaving behind $\mathrm{TiO}_{2}$ nanostructures in rice grain format. Under $\mathrm{NaOH}$ treatment, the rice grains transformed into sponge-like structures because of the leaching of $\mathrm{SiO}_{2}$. Hence, inherently, $\mathrm{SiO}_{2}$ assists the atomic rearrangement and has its role in the determining the morphology.

HRTEM is employed to reveal the local morphological and crystal structure. The results are shown in Fig. 4. Rice-grain structures (before $\mathrm{NaOH}$ treatment) are shown in Fig. 4(a). If we compare the diameters before and after $\mathrm{NaOH}$ treatment, we can see a dramatic increase. To be precise, the mean diameter is ca. $1.2 \mu \mathrm{m}$ (from Fig. 4(b)) for the $\mathrm{S}_{1}$ and $c a .1 .5 \mu \mathrm{m}$ (from Fig. 3(c)) for the $\mathrm{S}_{2}$. This increase indicates that after the $\mathrm{NaOH}$ treatment $\mathrm{TiO}_{2}-\mathrm{SiO}_{2}$ nanostructures (fibers/rice grains) have gone through a structural reorganization. The thorn morphology (after $\mathrm{NaOH}$ treatment, $\mathrm{S}_{1}$ ) is consistent with the SEM observation. Fig. 4(c) shows sponge shaped morphology of $\mathrm{S}_{2}$, where the edges appear like nanosheets or ribbons. The ribbon like structure is a vital observation where we have correlated these structures with the existing literature and the 

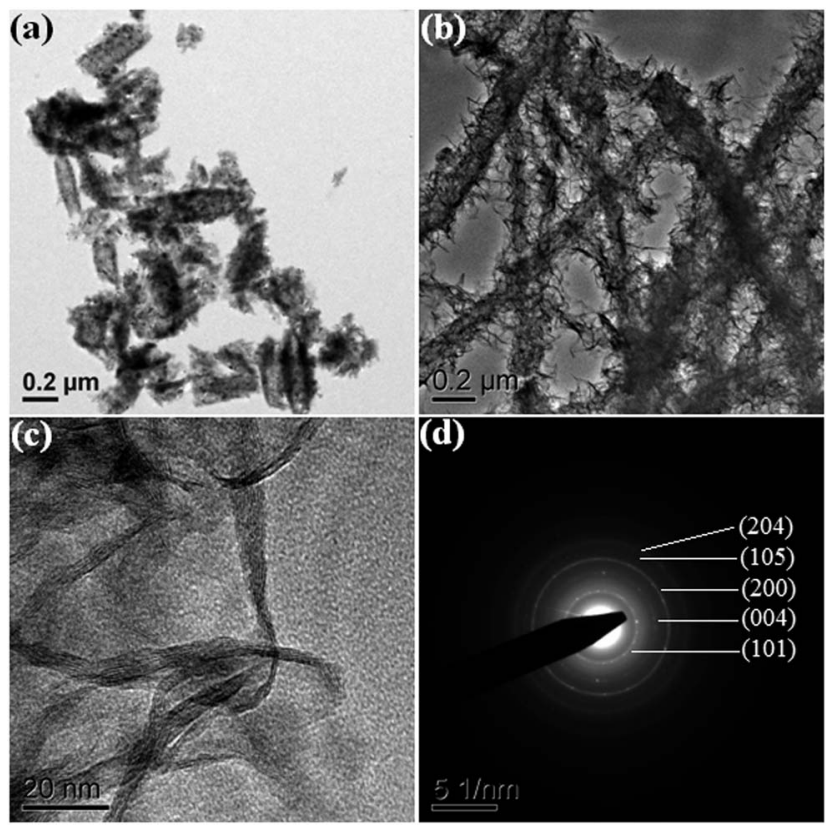

Fig. 4 High resolution TEM (a) rice grains $(b)$ thorn like structures $\left(S_{1}\right)$, (c) sponge like structure with ribbons on the edges $\left(\mathrm{S}_{2}\right)$ and (d) SAED pattern from $\mathrm{S}_{2}$ with diffraction planes annotated.

optical properties are discussed. The SAED pattern from sample $\mathrm{S}_{2}$ is shown in Fig. 4(d). We have annotated the diffraction planes on the image. These patterns suggest anatase phase titania. The resultant nanostructures were found to include $\mathrm{TiO}_{2}$ based nanostructured products. If we look at the SAED pattern closely we can see the bright spots in addition to the rings, where the earlier suggests highly crystalline material embedded in relatively low crystalline matrix. We will see that this polycrystalline nature is well evidenced in the context of XRD.

XRD patterns were recorded to understand the overall crystal structure of the titanates. Representative patterns for the $S_{1}, S_{2}$ and $\mathrm{S}_{3}$ are presented in Fig. 5. Interestingly these samples have shown similar pattern with differences in the relative intensity of each reflection. Major peaks are identified with their reflection planes on the image. Based on the results from XPS (not shown here, please consult ref. 39 for the details) and XRD establish the composition of the titanates to be $\mathrm{Na}_{2-x} \mathrm{H}_{x^{-}}$ $\mathrm{Ti}_{2} \mathrm{O}_{4}(\mathrm{OH})_{2}$. When such titanates are subjected to calcination above $450{ }^{\circ} \mathrm{C}$ the compound turns into $\mathrm{Na}_{2} \mathrm{Ti}_{2} \mathrm{O}_{4}(\mathrm{OH})_{2}$ (ref. 34 and 47 ) by loosing water. Further increase in the calcination temperature viz $700{ }^{\circ} \mathrm{C}$ completely destroys the nanostructure while turning them into nanoparticles, however $\mathrm{TiO}_{2}$ will be take rutile phase. Orthorhombic phase is identified and the lattice parameters for the $\mathrm{S}_{2}$ are $a=18.84 \AA, b=3.72 \AA$ and $c=$ $2.88 \AA$. The curved edges of sponge has taken its toll on XRD, where the diffraction peaks along the $Z$ axis ((301), (501), (002)) are relatively weaker than the other (Fig. 5 ). If we compare the lattice constant, $a$, of sponge sample with that of flat layered titanate $\mathrm{Na}_{4} \mathrm{Ti}_{9} \mathrm{O}_{20} \cdot x \mathrm{H}_{2} \mathrm{O}(a=17.2 \AA)^{48}$ and $\mathrm{Li}_{1.81} \mathrm{H}_{0.19^{-}}$ $\mathrm{Ti}_{2} \mathrm{O}_{5} \cdot 2.2 \mathrm{H}_{2} \mathrm{O}(a=16.66 \AA),{ }^{49}$ the distance between the adjacent

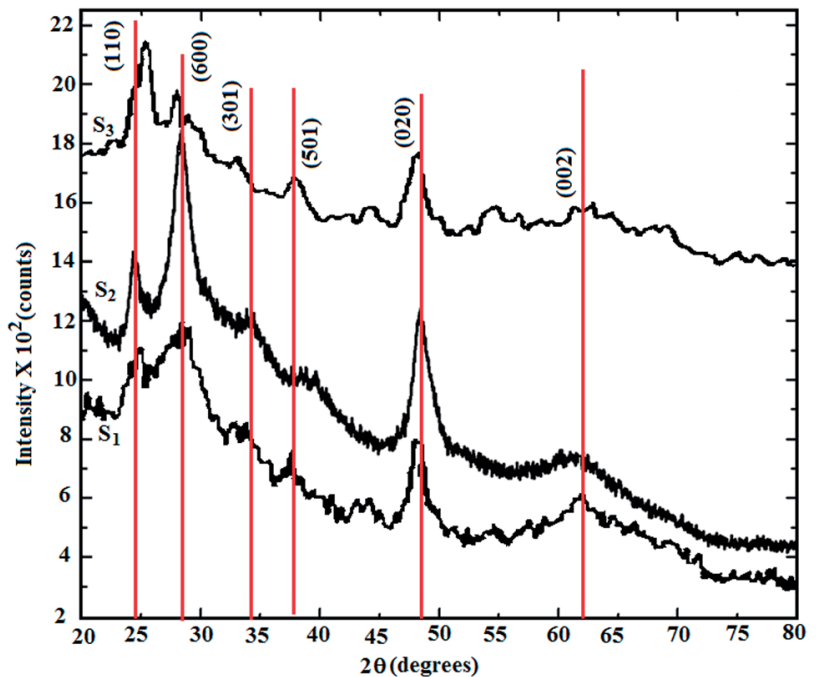

Fig. 5 XRD patterns of $S_{1}, S_{2}$, and $S_{3}$ titanates. The data from $S_{1}$ and $S_{3}$ are taken from our previous work. ${ }^{39}$

sheets $\left(a=2 \times d_{600}\right)$ for the sponge sample is larger than the other. In the case of (110) plane $S_{3}$ has shown compressive strain when compared to $S_{1}$ and $S_{2}$ samples. This might be because of relatively higher calcination temperature. Another notable difference is the shape of the peaks, especially for peak (600). This may be a result of $\mathrm{Na}^{+}$replacement by $\mathrm{H}^{+}$in $\mathrm{Na}_{2} \mathrm{Ti}_{2} \mathrm{O}_{4}(\mathrm{OH})_{2}$.

In general, the morphology can be modified via a selective dissolution or precipitation. Ti(rv) nucleates and transforms into porous titanate structures on alkali treatment. The reaction is as follows:

$$
2 \mathrm{TiO}_{2}+2 \mathrm{NaOH} \rightarrow \mathrm{Na}_{2} \mathrm{Ti}_{2} \mathrm{O}_{4}(\mathrm{OH})_{2}
$$

The open morphologies (or cavities), results in effective ionexchange properties while maintaining the rigidity. ${ }^{34}$ Ion exchangeability is the ratio between $\mathrm{Na}$ and $\mathrm{Ti}$ atoms in the nanostructures as varied with synthesis methods. ${ }^{47,50}$ The perfect crystal structures of $S_{1}, S_{2}$, and $S_{3}$ with concentrated $\mathrm{NaOH}$ can probably correspond to layered titanates; either $\mathrm{H}_{2} \mathrm{Ti}_{3} \mathrm{O}_{7}$ or $\mathrm{H}_{2} \mathrm{Ti}_{2} \mathrm{O}_{4}(\mathrm{OH})_{2}$ where they belong to monoclinic and orthorhombic crystals, respectively. Depending on the above two forms, the ion $\left(\mathrm{Na}^{+}, \mathrm{Me}^{n+}\right)$ exchange with proton $\left(\mathrm{H}^{+}\right)$can be represented by the following equations: ${ }^{47,50}$

$$
\begin{aligned}
x \mathrm{Me}^{n+}+\mathrm{H}_{2} \mathrm{Ti}_{3} \mathrm{O}_{7} & \rightarrow \mathrm{Me}_{x} \mathrm{H}_{2-x} \mathrm{Ti}_{3} \mathrm{O}_{7}^{x(n-1)+}+x \mathrm{H}^{+} \\
x \mathrm{H}^{+}+\mathrm{Na}_{2} \mathrm{Ti}_{2} \mathrm{O}_{4}(\mathrm{OH})_{2} & \rightarrow \mathrm{Na}_{2-x} \mathrm{H}_{x} \mathrm{Ti}_{2} \mathrm{O}_{4}(\mathrm{OH})_{2}+x \mathrm{Na}^{+}
\end{aligned}
$$

where $\mathrm{Me}^{n+}$ or $\mathrm{Na}^{+}$are cations and $x$ varies from 0 to 2 depending on $\mathrm{pH}$. Morphology differences may occur since, the $\mathrm{Na}^{+}-\mathrm{O}-\mathrm{Ti}$ bonds exist on the surface of the $\mathrm{TiO}_{2}$ and the overall charge is balanced. Once the structures treated distilled water and ethanol, these charges disappear, resulting in the formation of granular particles; the $\mathrm{Ti}-\mathrm{O}-\mathrm{Na}$ bonds may connect between the ends of the sheets and thus the formation of the rod like structures ${ }^{31}$ with thorn or sponges. 


\section{Carrier recombination-photoluminescence}

PL spectra have widely been used to investigate the efficiency of charge carrier trapping and recombination. The emission spectra from $S_{1}, S_{2}$ and $S_{3}$ samples are shown in Fig. 5. The PL spectra of titanate nanostructures may depict several bands resulting from shallow and deep trap transitions at shorter and longer wavelength regions, respectively. ${ }^{51}$ In contrast, here we observe only two bands above $450 \mathrm{~nm}$. From Fig. 6(a), a band centred at $\sim 463 \mathrm{~nm}(2.67 \mathrm{eV})$ is clearly observed, which is smaller than the band gap energy of typical titanate $(\sim 3.87$ and

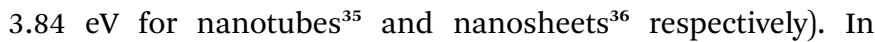
literature, titanate nanostructures produced by hydrothermal alkali treatment is seen to depict peaks at different wavelengths ${ }^{35}$ where the trapped cation governs the emission. Hence the emission bands are highly dependent on the composition of the surrounding media. ${ }^{3,52}$ Hence this band is attributed to the defect level transition associated with trapped cation, where we can see that the spectral location is not dependent on the morphology. A broad emission band at $\sim 533 \mathrm{~nm}$ appeared primarily due to the recombination of defects such as oxygen vacancies or surface states. ${ }^{53}$ The high surface area of the samples can lead to the formation of surface defects. To quantify the density of defects, $I_{\mathrm{UV}} / I_{\text {Defect }}$ is generally employed where the relative PL intensities reflect the optical quality. ${ }^{30,54}$ This quantification helps to understand the PCA of the samples as shown earlier. ${ }^{29,30}$ Higher ratio values suggests that the UV
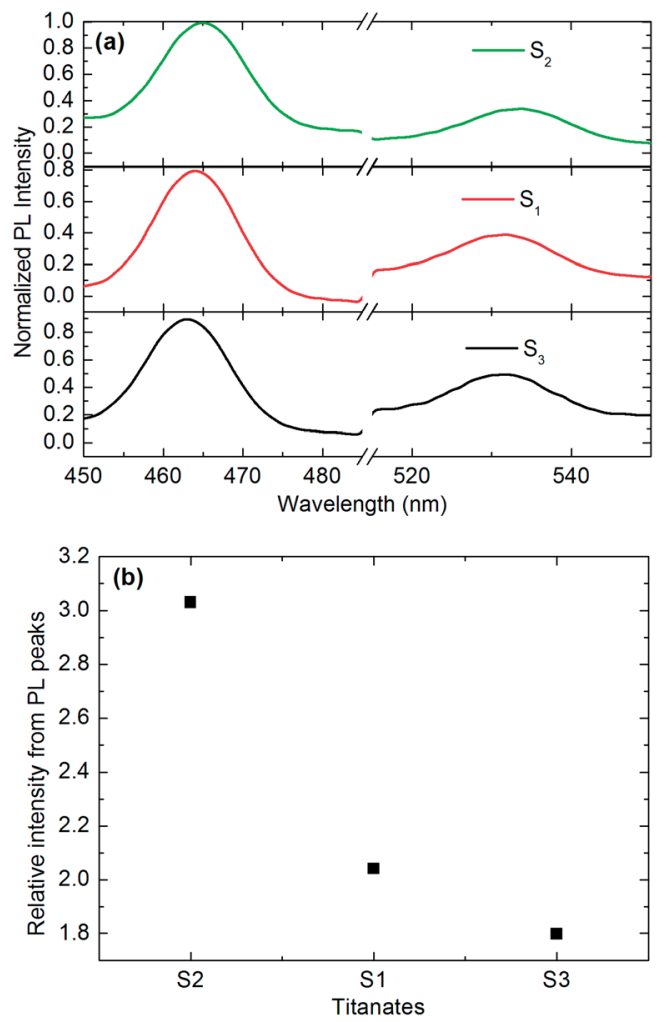

Fig. 6 (a) Photoluminescence from thorn like structures $\left(S_{1}\right)$, low temperature derived sponge sample $\left(\mathrm{S}_{2}, 500^{\circ} \mathrm{C}\right)$ and high temperature derived disintegrated-sponge sample $\left(\mathrm{S}_{3}, 700^{\circ} \mathrm{C}\right)$ and $(\mathrm{b})$ The relative $\mathrm{PL}$ intensity of the corresponding structures $\left(\mathrm{S}_{1}, \mathrm{~S}_{2}\right.$, and $\left.\mathrm{S}_{3}\right)$. emission is predominant where it can inferred that the band structure of the semiconductor is well established in terms of radiative recombination and the trap density is negligible. When the semiconductor is predominant with defects the UV emission is quenched similar to the present case where the interband transition is not observed. Hence, in order to compare the optical quality across these samples we have considered the ratio of defect emissions $\left(I_{463 \mathrm{~nm}} / I_{533 \mathrm{~nm}}\right)$ and the values are plotted in Fig. 6(b). Although both the emission are defect related, by doing this approximation at least we will be able to compare the relative defect densities. It is notable that $S_{3}$ has shown comparatively low ratio than the other two samples. Although it is observed that higher calcination temperatures produce samples with lesser oxygen related defects, ${ }^{51,55}$ the present context should be treated more carefully for two reasons. One of the two is that in those two cases, $\mathrm{SiO}_{2}$ is remains as a matrix in contrast to the present case where $\mathrm{SiO}_{2}$ is leached with $\mathrm{NaOH}$ treatment after the calcination. Hence the present effect is directly related to the leaching of $\mathrm{SiO}_{2}$ rather than a direct temperature effect. The second reasons is as follows. As discussed earlier, the sponge shaped titanates are produced after leaching with the background of a carrier polymer which shows relatively lower interaction. Due to the enhanced surface area the density of oxygen related defects are increased. On the other hand, we should note an exception in which $S_{1}$ and $S_{2}$ samples have been produced when calcined at the same temperature, the former sample has shown better optical quality. This discrepancy can be because of two reasons. First of all, the composition of the precursors is not the same for both the samples, where the former and latter use PVP and PVAc, respectively. The dynamics of both the polymers vary and hence a collective interaction among the precursors is expected. Furthermore, as discussed earlier, the differences in the interactions $\Delta_{1}$ and $\Delta_{2}$ caused severe effect on morphology so does the crystallinity. Note the variation in the relative intensities of various XRD peaks, which suggests that the average growth direction is not the same for all samples (Fig. 5). For example, (600) plane is predominant for $S_{1}$ and $S_{2}$, while (110) is for $S_{3}$. The difference in the predominant growth direction exposes other planes of the crystals to the environment, in which case the density of surface defects vary under thermal treatment. Second of all, the differences in the surface area due to sample morphology would have caused the discrepancy, where the $S_{1}$ has shown lower surface area than $\mathrm{S}_{2}, c f$. the surface area of $\mathrm{S}_{1}$ and $\mathrm{S}_{2}$ are 208 and $220 \mathrm{~m}^{2} \mathrm{~g}^{-1}$ respectively. ${ }^{39}$ As mentioned earlier, higher surface would cause higher density of defects. It is quite obvious that the defects are induced by thermal treatment up to a certain calcination temperature and above which they gradually disappear (e.g. $\left.750{ }^{\circ} \mathrm{C}\right) .{ }^{51,56}$ Among the three samples, $\mathrm{S}_{2}$ has the lowest density of defects, see Fig. 6(b). These defect states generally trap either electron or hole which would delay the recombination thus higher PCA in the context of $\mathrm{ZnO}$ (ref. 30) so does the case with $\mathrm{TiO}_{2} \cdot{ }^{29}$ Oxygen vacancies can be originated because of selective leaching of $\mathrm{SiO}_{2}$ through $\mathrm{NaOH}$ treatment. These defects states are found to delay the recombination process. ${ }^{\mathbf{2 8 - 3 0 , 5 7}}$ In the present context of oxygen related 
defects could have arose due to the breakage of bonds shown in the following equations. ${ }^{51,56}$

$$
\begin{gathered}
\equiv \mathrm{M}-\mathrm{OR}+\mathrm{H}_{2} \mathrm{O} \rightarrow \equiv \mathrm{M}-\mathrm{OH}+\mathrm{HOR} \\
2 \equiv \mathrm{M}-\mathrm{OH} \rightarrow \equiv \mathrm{M}-\mathrm{O}-\mathrm{M} \equiv+\mathrm{H}_{2} \mathrm{O}
\end{gathered}
$$

where $\mathrm{M}$ is denotes either $\mathrm{Ti}$ or $\mathrm{Si}$ and -OR denotes alkoxyl group. For the low temperature calcination (viz $500{ }^{\circ} \mathrm{C}$ ) large amount of $\equiv \mathrm{M}-\mathrm{OR}$ and $\equiv \mathrm{M}-\mathrm{OH}$ groups remain unchanged. In contrast, for high temperature calcination (viz $700{ }^{\circ} \mathrm{C}$ ), these bonds might break and form $\mathrm{TiO}_{2}$ and $\mathrm{SiO}_{2}$ via nucleation and crystallization. The earlier partially oxidized or broken $\equiv \mathrm{M}-\mathrm{OR}$ and $\equiv \mathrm{M}-\mathrm{OH}$ groups react differently from the latter $\mathrm{TiO}_{2}-\mathrm{SiO}_{2}$ composite, which is reflected as an explicit contrast in the morphologies. In the process of selective etching, the broken bonds can induce defect centers of different degree, where we have seen different relative intensities in PL (Fig. 6(b)). Furthermore, the differences in the ionic radii, viz $\mathrm{Ti}^{+4}(\sim 0.68 \AA)$ and $\mathrm{Si}^{+4}(\sim 0.41 \AA)$ could cause distortion in the lattice. Concluding, the differences in the intensities of radiative recombination is due to nanosized titanate crystallites (along with trapped cations), where it is originated due to the variation in calcination temperature and subsequent non-similar leaching of $\mathrm{SiO}_{2}$.

The band diagram of $S_{2}$ in comparison with the anatase $\mathrm{TiO}_{2}$, with respect to the $\mathrm{Ag} / \mathrm{Ag}^{+}$potentials is schematized in Fig. 6 . The band gap energy of the $S_{2}$ titanate and the anatase $\mathrm{TiO}_{2}$ are 3.8 (ref. 35) and $3.2 \mathrm{eV},{ }^{58}$ respectively. The valance band (VB) and conduction band (CB) edge positions of the titanates can be calculated from the following formulae (6) and (7) 59

$$
\begin{gathered}
E_{\mathrm{VB}}=\chi_{(\text {semiconductor })}-E_{\text {(free electrons) }}+0.5 E_{\mathrm{g}} \\
E_{\mathrm{CB}}=E_{\mathrm{VB}}-E_{\mathrm{g}}
\end{gathered}
$$

where $E_{\mathrm{g}}$ is the band gap energy; $E_{\mathrm{VB}}$ and $E_{\mathrm{CB}}$ are the VB and CB band edge potentials respectively, $\chi$ is the electronegativity (geometric mean) of the constituent atoms in a semiconductor, $E$ is the energy of free electrons with reference to the standard hydrogen electrode (SHE: $4.44 \pm 0.02 \mathrm{~V}$ at $25^{\circ} \mathrm{C}$ ). The calculated band edge positions of the titanates are presented in Fig. 6 . With reference to the SHE the flat band potentials are -1.27 , $-1.15 \mathrm{~V}$ and $2.05,2.53 \mathrm{~V}$ for $\mathrm{TiO}_{2}$ and sponge-TiO ${ }_{2}\left(\mathrm{~S}_{3}\right)$ respectively. From Fig. 6, the difference in the band gap of 0.6 $\mathrm{eV}$ has spread in $\mathrm{CB}$ and VB of titanate sample, where the band edges for $\mathrm{S}_{2}$ titanate is relatively higher than anatase $\mathrm{TiO}_{2}$.

PCA depends on the surface properties, availability of the photogenerated charge carriers and the energetic location of the $\mathrm{CB}$ and $\mathrm{VB} .{ }^{30}$ The relative $\mathrm{CB}$ and VB positions suggest that the photogenerated electron, hole exhibit stronger reduction and oxidation potentials in $\mathrm{S}_{2}$ than in anatase $\mathrm{TiO}_{2}$.

\section{Application of titanates for ARS dye removal through photocatalysis}

The titanate nanostructures have been potential for promising applications as adsorbents and photocatalysts for the removal of metal ions and dyes from wastewater. Titanates as nanostructures offer a large surface area, flexible interlayer distances ${ }^{50,60}$ high cation exchange capacity while providing channels for enhanced electron transfer. ${ }^{38}$ In general, the PCA of the photocatalyst depends on the particle size, surface area, defect density, optical quality and adsorbing ability. ${ }^{16,30}$ A high surface area can offer more active adsorption sites and photocatalytic reaction centers. The PCA of $S_{1}, S_{2}$, and $S_{3}$ samples is performed and shown in Fig. 7. The normalized concentration of the solution is equivalent to the normalized absorbance, ${ }^{27}$ so $A_{0} / A$ can be replaced with that of $C_{0} / C$. Clearly, the activity of the $\mathrm{S}_{2}$ is higher than the other samples. Nearly $72 \%$ of the dye degraded by $S_{2}$ which is superior than $S_{1}(53 \%)$ and the $S_{3}(56 \%)$ for an illumination of $5 \mathrm{~h}$. Rate constant for the degradation of dye is calculated using the equation $\left[\ln \left(C_{0} / C\right)=K t\right]$, where $C_{0}$ is the initial concentration of the dye and $C$ is the concentration of the dye at a time ' $t$ ', $K$ is the rate constant of the degradation would derived from plots. The fitting of absorbance plot versus time indicates an exponential decay as shown in Fig. 7(b). From the figure, first order pseudo rate constant ' $K$ ' is derived and found to be $0.00513,0.0104$ and $0.0064 \mathrm{~min}^{-1}$ for $S_{1}, S_{2}$ and $S_{3}$ respectively. The values are superior to that of earlier reported rate constant. ${ }^{16}$ The remarkable PCA for the sponge shaped titanates is attributed to their defective structure and high specific surface area. Surface area increases in the following order $S_{2}>S_{1}>S_{3}$ which shows a correlation with the relative optical quality of titanate and morphology. The high surface area sponge shapes enable to adsorb ARS molecules onto the surface of the pores, thus favouring the photocatalytic degradation. Higher surface area allows large amount dye to adsorb and henceforth degradation reaction. It means that the sponge shaped titanates would be expected to show more activity. From the above results, the sponge shaped titanates $\left(\mathrm{S}_{3}\right)$ will be promising for environmental and solar application.

The PCA of ARS dye mechanism is shown in Fig. 8. The pure ARS dye is adsorbed on the titanate catalyst. Photogenerated electrons transfer from VB to CB, leaving holes behind VB top of the ARS dye. Then the excited electrons react with the oxygen to form $\mathrm{O}_{2}{ }^{-}$. Then these oxygen radicals and holes can effectively

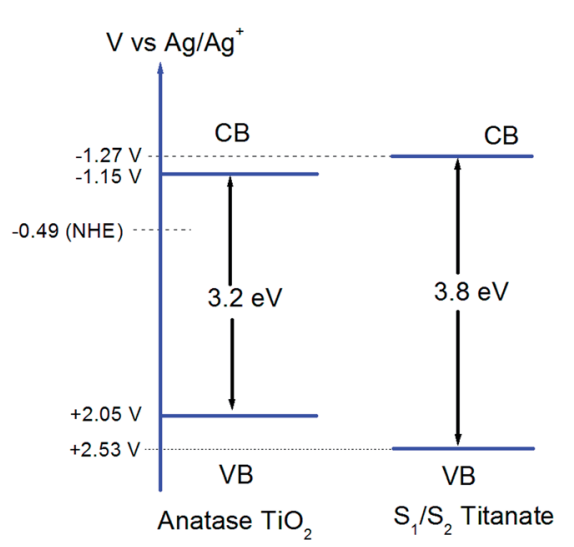

Fig. 7 Schematic representation of band diagram for thorn/sponge $\left(\mathrm{S}_{1} / \mathrm{S}_{2}\right)$ shaped titanate when compared with anatase $\mathrm{TiO}_{2}$. 

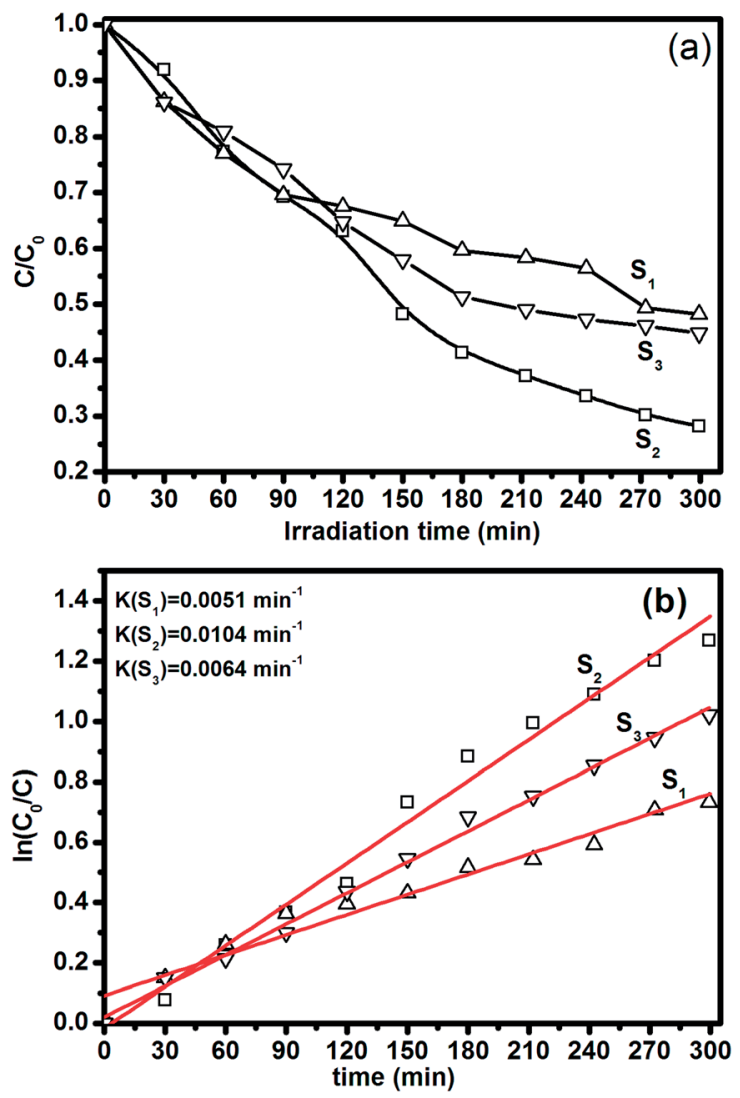

Fig. 8 (a) Photocatalytic activity of thorn sample $\left(\mathrm{S}_{1}\right)$, low temperature derived sponge sample $\left(\mathrm{S}_{2}, 500^{\circ} \mathrm{C}\right)$ and high temperature derived disintegrated sponge sample $\left(S_{3}, 700^{\circ} \mathrm{C}\right)$. (b) Kinetic plots; for $S_{1}, S_{2}$, and $\mathrm{S}_{3}$.

oxidize the ARS dye. Thus, it can be assumed that there are two possible mechanisms involved in the degradation (Fig. 9) process. $^{59}$

$$
\begin{gathered}
\mathrm{S}_{(\text {catalyst })}+h v \rightarrow \mathrm{h}^{+}+\mathrm{e}^{-} \\
\mathrm{e}^{-}+\mathrm{O}_{2} \rightarrow \mathrm{O}_{2}^{-} \text {(radical) } \\
\mathrm{h}^{+}+\mathrm{OH}^{-} \rightarrow \cdot \mathrm{OH} \text { (radical) }
\end{gathered}
$$

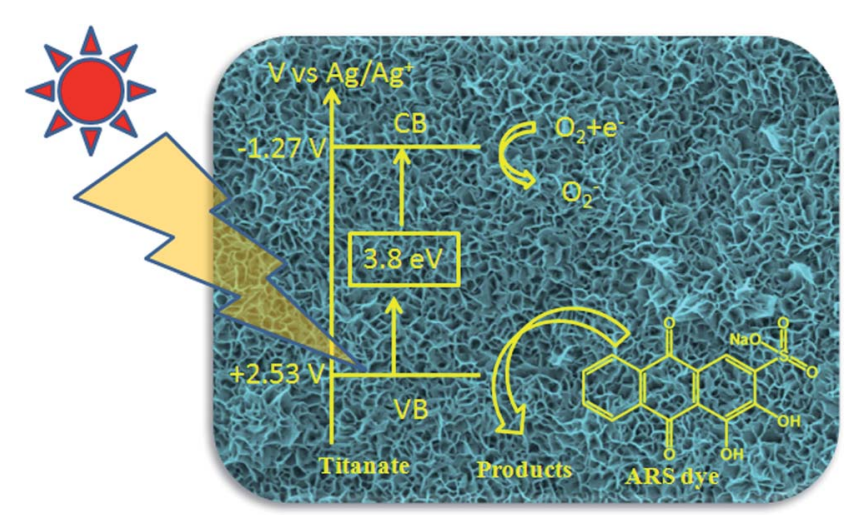

Fig. 9 Schematic representation of oxidation and reduction process.

$$
\begin{aligned}
& \operatorname{ARS}_{(\text {dye.ads) }}{ }^{*}+\mathrm{S}_{\text {(catalyst) }} \rightarrow \mathrm{S}_{\text {(catalyst) }}\left(\mathrm{e}^{-}\right)+\mathrm{ARS}_{(\text {dye.ads })}{ }^{+} \\
& \mathrm{S}_{\text {(catalyst) }}\left(\mathrm{e}^{-}\right)+\mathrm{O}_{2} \rightarrow \mathrm{S}_{(\text {catalyst })}+{ }^{\cdot} \mathrm{O}_{2}{ }^{-} \text {(radical) } \\
& \mathrm{S}_{\text {(catalyst) }}+{ }^{\cdot} \mathrm{O}_{2}{ }^{-}+2 \mathrm{H}^{+} \rightarrow \mathrm{S}_{(\text {catalyst })}+{ }^{\cdot} \mathrm{OH} \text { (radical) } \\
& \mathrm{ARS}_{(\text {dye.ads })}+{ }^{\cdot} \mathrm{O}_{2}{ }^{-} \rightarrow \text { products }
\end{aligned}
$$

where $\mathrm{S}$ stands for $\mathrm{S}_{1}, \mathrm{~S}_{2}$ or $\mathrm{S}_{3}$, and dye.ads stands for adsorbed dye. Through eqn (8-14) photocatalysis process takes place and consequently dye degradation.

\section{Conclusions}

Electrospun fibers/rice grain-shaped nanostructures of $\mathrm{TiO}_{2}-$ $\mathrm{SiO}_{2}$ composites are produced. Upon a treatment with conc. $\mathrm{NaOH}$ solution at $80{ }^{\circ} \mathrm{C}$ for $24 \mathrm{~h}$ results in highly anisotropic thorn and sponge shaped titanates with relatively high surface areas are reported. The as-obtained products were characterized by means of SEM, and TEM which confirmed their morphologies. Since the composition of precursor is not the same for both (thorn and sponge) samples, during calcination the dynamics of the polymers vary and the collective interaction between the precursors causes anisotropic crystal formation. This anisotropy is seen after $\mathrm{NaOH}$ treatment in terms of morphology, which also caused differences in the density of defects as seen in PL. Two emission bands are observed $(\sim 463$ and $\sim 533 \mathrm{~nm}$ ) are assigned to defects induced from the calcination, crystallization and nucleation effects. The relative PL intensities are increasing with increasing calcination-temperature which is in good agreement with the earlier reports. The relative PL intensity for highly porous sponge shapes was the lowest. This indicates that the sponge like nanostructures delays the $\mathrm{e} / \mathrm{h}$ recombination. The slower recombination rate is due to the abundant surface states when combined with high surface area results in enhanced PCA. Sponge shaped titanates exhibit higher degradation rate $\sim 0.01 \mathrm{~min}^{-1}$. A possible degradation mechanisms for the dye is proposed and discussed based on relative differences in the defect densities. We anticipate that our investigations may help further understanding of various titanate nanomaterials and accelerate in the application potential.

\section{Acknowledgements}

VJB, SV thanks The Scientific \& Technological Research Council of Turkey (TUBITAK) (TUBITAK-BIDEB 2221, Fellowships for visiting scientists and scientists on sabbatical leave) for providing fellowship.

\section{References}

1 E. Pelizzetti and C. Minero, Electrochim. Acta, 1993, 38, 4755.

2 M. M. Khin, S. Nair, J. b. Veluru, M. Rajendiran and S. Ramakrishna, Enery Environ. Sci., 2012, 5, 8075-8109. 
3 V. J. Babu, S. Vempati, S. Sundarrajan, M. Sireesha and S. Ramakrishna, Sol. Energy, 2014, 106, 1-22.

4 A. Nishimura, Y. Okano, M. Hirota and E. Hu, Int. J. Photoenergy, 2011, 2011, 305650.

5 V. J. Babu, M. K. Kumar, A. S. Nair, T. L. Kheng, S. I. Allakhverdiev and S. Ramakrishna, Int. J. Hydrogen Energy, 2012, 37, 8897-8904.

6 J. B. Veluru, K. K. Manippady, M. Rajendiren, K. M. Mya, P. R. Rayavarapu, S. N. Appukuttan and R. Seeram, Int. J. Hydrogen Energy, 2013, 38, 4324-4333.

7 D. V. Bavykin and a. F. C. Walsh, Eur. J. Inorg. Chem., 2009, 2009, 977-997.

8 X. Chen and S. S. Mao, Chem. Rev., 2007, 107, 2891-2959.

9 B. C. Viana, O. P. Ferreira, A. G. S. Filho, J. M. Filhob and a. O. L. Alvesa, J. Braz. Chem. Soc., 2009, 20, 167-175.

10 H. Y. Zhu, Y. Lan, X. P. Gao, S. P. Ringer, Z. F. Zheng, D. Y. Song and a. J. C. Zhao, J. Am. Chem. Soc., 2005, 127, 6730-6736.

11 D. J. Yang, Z. F. Zheng, H. Y. Zhu, H. W. Liu and a. X. P. Gao, Adv. Mater., 2008, 20, 2777-2781.

12 B. Zhao, F. Chen, W. Qu and J. Zhang, J. Solid State Chem., 2009, 182, 2225-2230.

13 C.-Y. Xu, Q. Zhang, H. Zhang, L. Zhen, J. Tang and a. L.-C. Qin, J. Am. Chem. Soc., 2005, 127, 11584-11585.

14 A. Riss, T. Berger, S. Stankic, J. Bernardi, E. Knözinger and O. Diwald, Angew. Chem., Int. Ed., 2008, 47, 1496-1499.

15 J.-q. Huang, Z. Huang, W. Guo, M.-l. Wang, Y.-g. Cao and a. M.-c. Hong, Cryst. Growth Des., 2008, 8, 2444-2446.

16 J. Huang, Y. Cao, Z. Deng and Hao Tong, J. Solid State Chem., 2011, 184, 712-719.

17 L. Torrente-Murciano, A. A. Lapkin, D. V. Bavykin, F. C. Walsh and K. Wilson, J. Catal., 2007, 245, 272-278.

18 C.-H. Han, D.-W. Hong, I.-J. Kim, J. Gwak, S.-D. Han and K. C. Singh, Sens. Actuators, B, 2007, 128, 320-325.

19 D. V. Bavykin, A. A. Lapkin, P. K. Plucinski, J. M. Friedrich and F. C. Walsh, J. Phys. Chem. B, 2005, 109, 19422-19427.

20 S. H. Lim, J. Luo, Z. Zhong, W. Ji and J. Lin, Inorg. Chem., 2005, 44, 4124-4126.

21 J. Li, Z. Tang and Z. Zhang, Chem. Mater., 2005, 17, 58485855.

22 H. Zhang, X. P. Gao, G. R. Li, T. Y. Yan and H. Y. Zhu, Electrochim. Acta, 2008, 53, 7061-7068.

23 Y. Lan, X. Gao, H. Zhu, Z. Zheng, T. Yan, F. Wu, S. P. Ringer and D. Song, Adv. Funct. Mater., 2005, 15, 1310-1318.

$24 \mathrm{H}$. Tokudome and M. Miyauchi, Angew. Chem., Int. Ed., 2005, 44, 1974-1977.

25 G.-S. Kim, H.-K. Seo, V. P. Godble, Y.-S. Kim, O.-B. Yang and H.-S. Shin, Electrochem. Commun., 2006, 8, 961-966.

26 E. Enache-Pommer, J. E. Boercker and E. S. Aydil, Appl. Phys. Lett., 2007, 91, 123116.

27 Q. Wan, T. H. Wang and a. J. C. Zhao, Appl. Phys. Lett., 2005, 87, 083105.

28 M. R. Hoffmann, S. T. Martin, W. Choi and D. W. Bahnemann, Chem. Rev., 1995, 95, 69-96.

29 F. Kayaci, S. Vempati, C. Ozgit-Akgun, I. Donmez, N. Biyikliab and T. Uyar, Nanoscale, 2014, 6, 5735-5745.
30 F. Kayaci, S. Vempati, C. Ozgit-Akgun, N. Biyikli and T. Uyar, Appl. Catal., B, 2014, 156-157, 173-183.

31 T. Kasuga, M. Hiramatsu, A. Hoson, T. Sekino and K. Niihara, Adv. Mater., 1999, 11, 1307-1311.

32 T. Kasuga, M. Hiramatsu, A. Hoson, T. Sekino and K. Niihara, Langmuir, 1998, 14, 3160-3163.

33 X. Sun and Y. Li, Chem.-Eur. J., 2003, 9, 2229-2238.

34 D. V. Bavykin, J. M. Friedrich and F. C. Walsh, Adv. Mater., 2006, 18, 2807-2824.

35 D. V. Bavykin, S. N. Gordeev, A. V. Moskalenko, A. A. Lapkin and F. C. Walsh, J. Phys. Chem. B, 2005, 109, 8565-8569.

36 N. Sakai, Y. Ebina, K. Takada and T. Sasaki, J. Am. Chem. Soc., 2004, 126, 5851-5858.

37 T. Kasuga, M. Hiramatsu, M. Hirano and A. Hoson, Chin. J. Mater. Res., 1997, 12, 607-609.

38 C.-K. Lee, S.-S. Liu, L.-C. Juang, C.-C. Wang, M.-D. Lyu and S.-H. Hung, J. Hazard. Mater., 2007, 148, 756-760.

39 A. S. Nair, Z. Peining, V. J. Babu, Y. Shengyuan, P. Shengjie and S. Ramakrishna, RSC Adv., 2012, 2, 992-998.

40 A. S. Nair, P. Zhu, V. J. Babu, S. Yang, T. Krishnamoorthy, R. Murugan, S. Peng and S. Ramakrishna, Langmuir, 2012, 28, 6202-6206.

41 V. J. Babu, A. S. Nair, Z. Peining and S. Ramakrishna, Mater. Lett., 2011, 65, 3064-3068.

42 Z. Peining, A. S. Nair, Y. Shengyuan and a. S. Ramakrishna, Mater. Res. Bull., 2011, 46, 588-595.

43 Y. Shengyuan, Z. Peining, A. S. Nair and a. S. Ramakrishna, J. Mater. Chem., 2011, 21, 6541-6548.

44 V. J. Babu, V. S. P. Kumar, G. J. Subha, V. Kumari, T. S. Natarajan, A. S. Nair and S. Ramakrishna, J. Eng. Fibers Fabr., 2011, 6, 54-59.

45 S. Vempati, Y. Ertas and T. Uyar, J. Phys. Chem. C, 2013, 117, 21609-21618.

46 S. M. Jo, M. Y. Song, Y. R. Ahn, C. R. Park and D. Y. Kim, J. Macromol. Sci., Part A: Pure Appl.Chem., 2005, 42, 1529-1540.

47 J. Yang, Z. Jin, X. Wang, W. Li, J. Zhang, S. Zhang, X. Guo and Z. Zhang, Dalton Trans., 2003, 3898-3901.

48 M. Sugita, M. Tsuji and M. Abe, Bull. Chem. Soc. Jpn., 1990, 63, 1978-1984.

49 T. Sasaki, M. Watanabe, Y. Komatsu and Y. Fujiki, Inorg. Chem., 1985, 24, 2265-2271.

50 D. V. Bavykin, A. A. Lapkin, P. K. Plucinski, J. M. Friedrich and F. C. Walsh, J. Catal., 2005, 235, 10-17.

51 C. F. Song, M. K. Lu, P. Yang, D. Xu and D. R. Yuan, Thin Solid Films, 2002, 413, 155-159.

52 H. Xin, R. Ma, L. Wang, Y. Ebina, K. Takada and T. Sasaki, Appl. Phys. Lett., 2004, 85, 4187.

53 J. Jun, C. Jin, H. Kim, J. Kang and C. Lee, Appl. Phys. A, 2008, 96, 813-818.

54 S. Vempati, A. Shetty, P. Dawson, K. Nanda and S. B. Krupanidhi, J. Cryst. Growth, 2012, 343, 7-12.

55 C. F. Song, M. K. Lü, S. F. Wang, D. Xu, D. R. Yuan and G. J. Zhou, Inorg. Mater., 2003, 39, 1326-1328.

56 I. I. Hinic, G. M. Stanisic and Z. V. Popovic, J. Sol-Gel Sci. Technol., 1999, 14, 281-289.

57 S. Hu, F. Li and Z. Fan, Bull. Korean Chem. Soc., 2012, 33, 1895-1899. 
58 D. O. Scanlon, C. W. Dunnill, J. Buckeridge, S. A. Shevlin, A. J. Logsdail, S. M. Woodley, C. R. A. Catlow, M. J. Powell, R. G. Palgrave, I. P. Parkin, G. W. Watson, T. W. Keal, P. Sherwood, A. Walsh and A. A. Sokol, Nat. Mater., 2013, 12, 798-801.
59 J. B. Veluru, R. R. S. Bhavatharini and S. Ramakrishna, RSC Adv., 2014, 4, 19251-19256.

60 Q. Chen, G. H. Du and S. L. M. Z. Peng, Acta Crystallogr., Sect. B: Struct. Sci., 2002, 58, 587. 